\title{
Desafios teórico-metodológicos da relação Educação e Patrimônio*
}

\author{
Theoretical-methodological challenges \\ of Education and Heritage
}

\begin{abstract}
Júnia Sales Pereira
Doutora em História (UFMG) e professora da Faculdade de Educação da UFMG juniasales@gmail.com
\end{abstract}

\author{
Ricardo Oriá \\ Doutor em História da Educação (USP), consultor \\ legislativo/Museu da Câmara dos Deputados \\ groof@uol.com.br
}

\section{Resumo:}

Abordagem de concepçóes renovadas a respeito da Educação e Patrimônio, levando-se em conta as transformaçóes culturais contemporâneas e o adensamento das concepçóes de patrimônio advindas da consideração da imaterialidade da cultura. Análise do caráter intersubjetivo, multidirecional, relacional e processual dos processos educativos com enunciação de revisões conceituais e metodológicas impactantes em projetos que vislumbram a educação das sensibilidades em meio às lutas pela preservação e junto a embates dos diferentes sujeitos/grupos históricos contra a destruição, o esquecimento e o silenciamento da memória.

Palavras-chave: Memória; Educação; Patrimônio Cultural

\section{Abstract:}

Renewed approach to conceptions about the Education and Heritage, taking into account changes and contemporary cultural transformations and density conceptions of heritage from consideration of the immateriality of the culture. Analysis of the intersubjective character, and multidirectional, relational and procedural aspects of educational processes with enunciation of conceptual and methodological revisions impacting on projects that envision the education of sensitivities in the midst of struggles to preserve and along the clashes of different subjects / historical groups against destruction, oblivion and the silencing of memory.

Keywords: Memory; Education; Cultural Heritage

* Trabalho apresentado no GT Memória e Educação Patrimonial 
o realizar um balanço da historiografia contemporânea, o his-
toriador francês Pierre Nora, organizador da clássica obra Les
Lieux de Memoire, disse, de forma muito apropriada, que:

Em todo o mundo, estamos experimentando a emergência da memória (...) Durante os últimos vinte a vinte e cinco anos, todos os países, todos os grupos sociais e étnicos, passaram por uma profunda mudança, mesmo uma revolução, no relacionamento tradicional que tem mantido com seu passado. Essa mudança tem adotado múltiplas e diferentes formas, dependendo de cada caso individual: uma crítica das versôes oficiais da História; a recuperação dos traços de um passado que foi obliterado ou confiscado; o culto às raízes, ondas comemorativas de sentimento; conflitos envolvendo lugares ou monumentos simbólicos; uma proliferação de museus; aumento da sensibilidade relativa à restrição de acesso ou à exploração de arquivos; uma renovaçáo do apego aquilo que em inglês é chamado de heritage e em francês patrimoine; a regulamentaçáo judicial do passado. Qualquer que seja a combinação desses elementos, é como uma onda de recordação que se espalhou através do mundo e que, em toda a parte, liga firmemente a lealdade ao passado - real ou imaginário - e a sensaçáo de pertencimento, consciência coletiva e autoconsciência. Memória e identidade (NORA, 2009: 6).

Outros historiadores e cientistas sociais comungam dessa mesma ideia. O inglês Peter Burke chega a afirmar que vivemos, desde os últimos anos do século passado, um verdadeiro "boom da memória", caracterizado pelas excessivas ondas de comemoração de efemérides históricas (BURKE, 2009). Por sua vez, o antropólogo Andreas Huyssen diz que estamos todos "seduzidos pela memória”: "um dos fenômenos culturais e políticos mais surpreendentes dos anos recentes é a emergência da memória como uma das preocupaçóes culturais e políticas das sociedades ocidentais." Para ele, “...a memória se tornou uma obsessão cultural de proporçóes monumentais em todos os pontos do planeta” (HUYSSEN, 2000: 9-16).

No Brasil, não é diferente. A cada dia presenciamos a criação de novos museus, centros de pesquisa e documentação, desenvolvimento de projetos de história oral em associações comunitárias e de histórias institucionais por parte de órgãos do governo e empresas. Por sua vez, desde meados dos anos 1980, os movimentos sociais populares, encetados por novos atores sociais na cena política (mulheres, índios, negros, sem-terra, homossexuais etc.) vêem no "resgate" de sua memória um instrumento poderoso de afirmação de sua identidade e de luta pelos direitos de cidadania. Assim, como ocorre em outras partes do mundo, assistimos nos últimos decênios a uma preocupação maior com questóes atinentes às políticas de memória e à preservação do Patrimônio Cultural.

Nesse contexto, várias organizaçóes governamentais e da sociedade civil vêm desenvolvendo açóes voltadas para o conhecimento e valorização de seu acervo histórico-cultural. Hoje, alguns historiadores e profissionais que lidam 
com a dimensão da memória vêm propondo no âmbito de suas instituições culturais, sobretudo em museus, a elaboraçáo de programas de açáo educativa ou, como pretendem alguns, atividades de "Educação Patrimonial".

Mas o que vem a ser Educação Patrimonial? Quais as possíveis relaçóes que se podem estabelecer entre Educação e Patrimônio? É possível uma Educação para o Patrimônio, não apenas reduzida a uma mera técnica de ensino, mas enquanto dimensão processual que sensibilize alunos, professores e comunidade escolar na construção de sua(s) memória(s)?

\section{Educação e Patrimônio: uma relação antiga}

Podemos afirmar que a preocupação com a dimensão educativa do $\mathrm{Pa}$ trimônio Histórico encontra-se presente desde sua formulação moderna, em meados do século XVIII. Após o processo revolucionário francês, elaborou-se um modelo de organização da cultura nacional francesa pautada na preservação, conhecimento e valorização dos bens culturais reveladores do passado histórico. Essa iniciativa partiu dos enciclopedistas preocupados com os efeitos do "vandalismo" praticado pelos "exércitos negros", criados para destruir os símbolos e ícones do Antigo Regime. Surge, assim, o conceito moderno de Patrimônio, cuja matriz francesa serviu de modelo e inspiração para a intelligentsia brasileira.

Preservar o patrimônio histórico da nação constitui, antes de tudo, uma missão educativa, pois o que se pretende com essa ação é levar ao conhecimento das geraçóes futuras o passado nacional com o objetivo de fortalecimento da identidade e do sentimento de pertencimento dos cidadãos. Em última instância é a herança cultural das geraçôes passadas que se lega à posteridade e isso nada mais é do que, em sentido mais amplo, promover a educação.

Segundo Fonseca, a política de preservação do Patrimônio Histórico na França e em vários países do mundo ocidental assumiu uma dupla dimensão, a saber:

- a dimensão cívica, na medida em que determinados bens culturais são convertidos em testemunhos privilegiados da memória da nação, e passam a ser protegidos por leis que ordenam sua proteçáo, cuidados por instituiçôes criadas especificamente para esse fim, e divulgados por meio da instrução pública e leiga;

- a dimensão estética, na medida em que, como signos do passado, os monumentos integram a iconografia e o imaginário romântico, em que a Idade Média era tema recorrente e as ruínas um motivo muito frequente (FONSECA, 2007: 165).

No Brasil, em plena década de 1920, quando se inicia a discussão sobre a necessidade de preservação de nosso passado, no contexto do movimento modernista, Mário de Andrade já atestava o valor do nosso Patrimônio Histórico como forma constitutiva da identidade nacional, assentada na pluralidade de nossas raízes e matrizes étnicas. Não muito compreendido à sua época, Mário de Andrade pode ser considerado um dos pioneiros autores que alertaram para a face imaterial da cultura e para a diversidade de registros constitutiva do patrimônio cultural brasileiro. Somente o conhecimento da cultura em suas dimensóes múl- 


\section{Artigos \& Ensaios}

1 - O Prêmio Rodrigo Melo Franco de Andrade concedido anualmente pelo IPHAN às melhores ações de preservação do País contempla, entre outras categorias, a modalidade de Educação Patrimonial. tiplas daria condições de o Brasil inserir-se no concerto das naçóes e esse trabalho deveria iniciar-se juntamente com o processo de escolarização. Dizia ele: "O ensino primário é imprescindível (...). Não basta ensinar o analfabeto a ler. É preciso dar-lhe contemporaneamente o elemento em que possa exercer a faculdade que adquiriu. Defender o nosso patrimônio histórico e artístico é alfabetização" (SILVA, 1992: 23).

A necessidade da utilização do acervo cultural brasileiro enquanto objeto de estudo nos currículos e programas escolares já se constituía uma preocupação dos ideólogos do Patrimônio Cultural, a exemplo de Rodrigo Melo Franco de Andrade[1]. Para ele, só havia um meio eficaz de assegurar a defesa do patrimônio histórico e artístico nacional - a educação popular.

Portanto, a política de Patrimônio Histórico esteve sempre atrelada à ideia de que a preservação dos bens culturais estivesse associada ao processo educativo das novas geraçóes. $\mathrm{Na}$ prática, isso nem sempre aconteceu, sobretudo em um país como o nosso em que as políticas culturais e educacionais sofrem de solução de continuidade.

Em meados dos anos 1980, com a experiência da museóloga Maria de Lourdes Horta, desenvolveu-se e disseminou-se nas instituiçôes culturais brasileiras o conceito de Educação Patrimonial, difundida sob o signo das discussóes promovidas a partir do grupo que se articulou no Museu Imperial naquele momento e das influências teóricas difundidas no período. "Educação Patrimonial" é uma expressão de origem inglesa (Heritage Education) e pode ser traduzida como "um instrumento de alfabetização cultural, que possibilita ao indivíduo fazer a leitura do mundo que o rodeia, levando-o à compreensão do universo sociocultural e da trajetória histórico-temporal em que está inserido" (grifos nossos) (HORTA, 1999: 6). Segundo ela, a Educação Patrimonial possibilita o reforço da autoestima dos indivíduos e das comunidades e a valorização da cultura brasileira em sua rica diversidade.

Em que pese o pioneirismo de sua ação no âmbito do Museu Imperial de Petrópolis, consideramos que o modelo proposto é meramente instrumental e se concentra na análise do objeto museológico em si, preterindo outras dimensóes importantes do processo educativo, ou seja, os sujeitos da aprendizagem e que são, também, sujeitos históricos. Devemos ressaltar, também, o fato de que o que se formula como Educação Patrimonial, então, situa-se num contexto histórico de lutas pela manutenção, conservação e registro de bens de natureza material, uma luta, digamos, contra a destruição dos registros históricos nacionais. No seio daquela discussão, portanto, o conceito de Educação Patrimonial nasce tributário das lutas sociais e institucionais pela preservação dos registros patrimoniais (inclusive e sobretudo aqueles vinculados à identidade nacional e, em especial, os bens culturais consagrados).

Como não poderia ser diferente, as transformaçóes sociais, políticas, educacionais e culturais marcaram, desde então, profundamente as concepçóes acerca do Patrimônio Cultural e, por suposto, a Educação.

Hoje, pluralizam-se as denominaçóes: Educação com o patrimônio, Educação para o patrimônio, Educação e Patrimônio. Pluralizaram-se também os lugares e suportes da memória (museus, monumentos históricos, arquivos, bibliotecas, sítios históricos, vestígios arqueológicos, festas, ofícios, saberes e fazeres etc.) no processo educativo, a fim de desenvolver a sensibilidade e a consciência dos educandos e dos cidadãos para a importância da preservação desses bens 
culturais. Professores e alunos abordam o Patrimônio Cultural como construção histórica e seletiva da memória de uma dada comunidade, em suas dimensôes sensíveis, éticas e políticas.

Ao contrário dos que muitos apregoam, a inserção de temas relacionados com a questão do Patrimônio Histórico não se dará pela criação de mais uma disciplina ao já saturado currículo escolar da educaçáo básica. Entendemos que a Educação Patrimonial, ao articular conteúdos de diferentes áreas do conhecimento, sobretudo da área de Ciências Humanas e Sociais, requer um tratamento interdisciplinar e contextualizado por parte da escola, no âmbito de seu projeto político-pedagógico.

Mais ainda, como já dissemos, está em curso uma transformação conceitual, teórico e prática nas abordagens educativas do patrimônio, evidentemente com concepçóes contrastantes, num diálogo tenso e criativo entre tradição e inovação.

\section{Patrimônio Cultural: novos paradigmas PARA A PRESERVAÇÁ̃O E PARA A EDUCAÇÁO}

Quando se fala em Patrimônio Histórico a primeira imagem que nos vem à mente, consagrada no senso comum e marcada pelas seleçóes históricas, é aquela identificada com as cidades coloniais, com os monumentos, com as edificaçóes antigas, com as obras de arte e com os sítios arqueológicos. Nas últimas décadas do século XX ocorreu uma ampliação da noção de patrimônio histórico para a de patrimônio cultural.

A perspectiva reducionista inicial, que reconhecia o patrimônio apenas no âmbito histórico, circunscrito a recortes cronológicos arbitrários e permeados por episódios militares e personagens emblemáticos, acabou sendo, aos poucos, suplantada por uma visão muito mais abrangente. A definição de patrimônio passou a ser pautada pelos referenciais culturais dos povos, pela percepção dos bens culturais nas dimensóes testemunhais do cotidiano e das realizaçóes intangíveis (FUNARI e PELEGRINI, 2006: 31-2).

Esta alteração marcará profundamente os processos educativos, convocando as faces intangíveis do patrimônio e os fazeres e saberes cotidianos, tão caros às práticas educativas dos docentes. Interrogamo-nos se estas transformaçóes já estariam, entâo, em curso nas escolas, em práticas docentes silenciosas, saltando à cena a partir de sua aceitação...

Face à renovação epistemológica das Ciências Sociais, em especial da Antropologia, o conceito de Patrimônio Histórico foi ampliado, para além da sua dimensão "pedra e cal", ou seja, aquela restrita aos bens materiais edificados que foram alvo prioritário da açáo preservacionista do Estado em contextos de destruição.

A Constituição Federal de 1988 acompanhou essa nova conceituação. Um só artigo específico trata da conceituação, caracterização e formas de preservação do acervo histórico do País. No seu art. 216, usa-se a expressão "Patrimônio Cultural" em substituição a "Patrimônio Histórico e Artístico", que vinha sendo 
usada desde a Carta de 1937. Assim, seguindo a moderna orientação adotada pelas Ciências Sociais, o legislador constituinte ampliou a interpretação do que seja Patrimônio Cultural que, pelo texto constitucional vigente, engloba

... os bens de natureza material e imaterial, tomados individualmente ou em conjunto, portadores de referência à identidade, à ação, à memória dos diferentes grupos formadores da sociedade brasileira, nos quais se incluem: as formas de expressão; os modos de criar, fazer e viver; as criações científicas, artísticas e tecnológicas; as obras, objetos, documentos, edificaçóes e demais espaços destinados às manifestaçóes artístico-culturais; e os conjuntos urbanos e sítios de valor histórico, paisagístico, artístico, arqueológico, paleontológico, ecológico e científico (art. 216 da Constituição Federal).

Adota-se, portanto, uma noção mais abrangente de Patrimônio Cultural e se rompe com a visáo elitista que considerava apenas objeto de preservaçáo cultural as manifestaçóes de classes historicamente dominantes, incorporando, a partir de então, os registros e modos de expressar a cultura de diferentes grupos étnicos e sociais que contribuíram e contribuem para a formação da sociedade brasileira. No seio desta transformação também enuncia-se nova abordagem educativa do patrimônio, convocada pela dinamicidade e processualidade da cultura.

O novo conceito de Patrimônio Cultural vem ao encontro do anseio do escritor paulista Mário de Andrade, um dos intelectuais mais atuantes do Movimento Modernista de 1922 e que, no seu anteprojeto, já delineava essa concepção abrangente de Patrimônio Histórico. Posteriormente, Aloísio Magalhães, à frente da extinta Fundação Nacional Pró-Memória, tentou retomar essa concepção que agora já é praticada pelo atual Instituto do Patrimônio Histórico e Artístico Nacional (IPHAN), a partir da edição do Decreto no 3.551, de 2000, que criou a figura jurídica do registro para a preservação dos bens culturais imateriais.

Hoje, como bem sabemos, o Patrimônio Cultural de uma dada coletividade contempla uma gama de bens, seja de ordem material ou intangível. Mas nem sempre foi assim. Tomemos a ação do IPHAN na sua chamada "fase heroica", liderada por Rodrigo Melo Franco de Andrade.

Em que pese a atuação ímpar do antigo SPHAN, desde a sua criação em 1937, impedindo a destruição de importantes sítios, cidades e monumentos históricos identificados com o barroco colonial, não podemos deixar de registrar que essa política preservacionista trouxe algumas consequências para a vida política cultural brasileira, com desdobramentos nos processos educativos voltados à compreensão e usufruto do patrimônio.

$\mathrm{Na}$ verdade, a política de patrimônio, ao privilegiar o instrumento jurídico do tombamento em sua ação preservacionista, consagrou uma memória nacional vinculada apenas a determinados segmentos da sociedade e a um estilo arquitetônico predominante, no caso, o barroco. Por força da legislação ainda vigente (Decreto-Lei no 25/37), o conceito de Patrimônio Histórico esteve restrito ao "conjunto de bens móveis e imóveis existentes no país e cuja conservação seja de interesse público, quer por sua vinculação a fatos memoráveis da História do Brasil, quer por seu excepcional valor arqueológico ou etnográfico, bibliográ- 
fico ou artístico". (grifos nossos). Os conceitos de monumentalidade do bem e de excepcionalidade de seu valor nortearam, na prática, a política de preservação do Patrimônio Histórico no País. Priorizou-se, assim, o patrimônio edificado e arquitetônico, em detrimento de outros bens culturais significativos, mas que, por não serem representativos de uma determinada época ou ligados a algum fato histórico notável ou pertencente a um estilo arquitetônico relevante, deixaram de ser preservados e foram relegados ao esquecimento e até destruídos por não terem, no contexto dessa concepção histórica, valor que justificasse a sua preservação. A esta concepção de patrimônio e de preservação vincula-se uma proposição educativa voltada à compreensão do passado histórico (sem, necessariamente, vincular-se ao presente vivido), à heroicização das açóes e sujeitos históricos, à compreensão do histórico como excepcional, raro e materialmente valioso.

Essa política de Patrimônio Histórico deixou um saldo de bens tombados, sobretudo imóveis, referentes aos setores dominantes da sociedade brasileira. Houve uma "política de patrimônio que preservou a casa-grande, as igrejas barrocas, os fortes militares, as casas de câmara e cadeia como as referências para a construção de nossa identidade histórica e cultural e que relegou ao esquecimento as senzalas, as favelas e os bairros operários" (FERNANDES, 1993: 275).

Essa política de preservação que norteou a prática do SPHAN objetivava passar a ideia de uma memória mítica, de um passado homogêneo e uma História sem conflitos e contradiçôes sociais (CANCLINI, 1994). A concepção predominante era a de percepção de um passado unívoco, forjado por uma memória nacional única, excluindo as diferenças e a riqueza de nossa pluralidade cultural, evidenciada através de outras matrizes étnicas que contribuíram na formação do "nacional".

Em síntese, podemos afirmar que, no Brasil, a preservação do Patrimônio Histórico nasceu sob a égide estatal, ou seja, em última instância, foi quase sempre o Poder Público quem determinou o que deveria ou náo ser preservado, o que deveria ser lembrado ou esquecido (LE GOFF, 1990; RICOEUR, 2007). Construiu-se uma memória nacional oficial, excludente e celebrativa dos feitos dos "heróis nacionais". Privilegiou-se o barroco como ícone da identidade nacional e excluíram-se outros estilos estéticos, como o neoclássico, o art-nouveau, o neocolonial e o ecletismo. Elegeram-se determinados bens como representativos da memória nacional em detrimento de outros, que pudessem mostrar "a cara" multifacetada e pluriétnica do país.

\section{PATRIMÔNIO CULTURAL - QUADRO SINÓPTICO}

\begin{tabular}{|l|l|l|}
\hline PARADIGMA & SÉCULO XX & SÉCULO XXI \\
\hline 1. Terminologia & Patrimônio Histórico e Artístico & Patrimônio Cultural \\
\hline $\begin{array}{l}\text { 2. Objeto e instrumento de } \\
\text { preservação }\end{array}$ & $\begin{array}{l}\text { Bens materiais (imóveis)- } \\
\text { Tombamento }\end{array}$ & $\begin{array}{l}\text { Bens materiais e } \\
\text { imateriais- Registro }\end{array}$ \\
\hline 3. Objetivo & Construção da Identidade Nacional & Promoção da Diversidade Cultural \\
\hline 4. Vetor de preservação & $\begin{array}{l}\text { Excepcionalidade, autenticidade e } \\
\text { monumentalidade }\end{array}$ & $\begin{array}{l}\text { Referencialidade e Pertencimento } \\
\text { 5. Esfera de atuação }\end{array}$ \\
Poder Público (nível federal) & $\begin{array}{l}\text { Poder Público (nível municipal), } \\
\text { sociedade civil e setor privado }\end{array}$ \\
\hline
\end{tabular}

Hoje, preservar o Patrimônio Cultural é, acima de tudo, uma questão de cidadania: todos temos o direito à memória, mas também o dever de zelar pelos bens de nossa diversidade cultural. Assim, a política de preservação e usufruto de 
nossa memória deve ser encarada não como uma questão do passado, mas sim, como uma tarefa de todos os brasileiros no presente. São os homens e as mulheres no presente que elegem os bens culturais reveladores de seu passado e de seu presente para a constituição de sua identidade como sujeitos históricos e cidadãos plenos que constroem coletivamente suas múltiplas memórias.

Há, na contemporaneidade, em especial com o retorno/formulação da noção de imaterialidade da cultura, uma distensão temporal e conceitual que possibilita a recuperação e localizaçáo dos movimentos dos quais a noçáo de patrimônio é tributária. Segundo Gonçalves,

Muitos são os estudos que afirmam constituir-se essa categoria [patrimônio] em fins do século XVIII, juntamente com os processos de formação dos Estados nacionais, o que é correto. Omite-se, no entanto, seu caráter milenar. Ela não é simplesmente uma invenção moderna. Está presente no mundo clássico e na Idade Média. A modernidade ocidental apenas impóe contornos semânticos específicos assumidos por ela. Podemos dizer que a categoria "patrimônio" também se faz presente nas sociedades tribais (GONÇALVES, 2009: 26).

Não custa dizer que este alargamento temporal é, também, conceitual e com desdobramentos sensíveis nos processos educativos para registro e usufruto do patrimônio.

\section{Memória, Educação e Patrimônio: um diálogo possível}

A ampliação do conceito de Patrimônio Cultural e dos novos paradigmas de preservação da memória acarretaram repercussão no mundo da educaçáo. $\mathrm{Na}$ verdade, a admissão das dimensóes imateriais do Patrimônio Cultural altera as práticas educativas fundamentalmente porque admite um universo ampliado de bens como participantes dos gestos de referenciação patrimonial, com foco nas relaçóes intersubjetivas mediadas pelas noçôes afetas ao patrimônio. Náo se trata apenas ou simplesmente de uma ampliação de bens de patrimônio, mas de uma mudança de concepção. A noção de patrimônio imaterial requer a consciência do que mais do que preservar um objeto como testemunho de um processo histórico, é necessário valorizar os saberes que o produz, permitindo a vivência de tradições, saberes, saber-fazer, conhecimentos, celebraçôes, práticas, sonoridades etc., no tempo presente. As concepçóes que orientam os registros de patrimônio imaterial requerem reorientação dos processos educativos para percepção do patrimônio como vivente na vida em curso. De certa forma, o que orientava os processos educativos, no tocante ao patrimônio, até determinado momento, sobretudo até o advento da legislação sobre patrimonio imaterial, orientava-se, grosso modo, tendo o passado histórico e cultural como centralidade. Muda a relação temporal nos processos educativos como também o foco de abordagem.

Dos processos que envolvem o patrimônio imaterial surgem orientaçóes voltadas à compreensão cultural vincada ao tempo presente, às expressóes vivas e em movimento permanente. Há, portanto, vários deslocamentos advindos desta questão, na relação entre educação e patrimônio, sobretudo porque consideram os mecanismos de usufruto como partícipes da patrimonialização. 
Afirma-se uma concepção de educação orientada à percepção da processualidade da cultura e à sua dinamicidade, o que implica compreender o patrimônio em sua mutabilidade e movência. Uma segunda orientação advinda destas transformaçôes diz respeito à necessária ampliação das dimensôes sensíveis na abordagem educativa, com inclusão de percepçóes, sensaçóes, e da capacidade imaginativa dos sujeitos na produção da cultura. Além disso, o processo educativo convoca, necessariamente, neste novo cenário, a face investigativa da cultura, com convocação de tradiçóes, saberes, conhecimentos, festejos, celebraçóes, que são do universo cultural dos sujeitos participantes do ato educativo.

Há deslocamentos, também, na própria noção de preservação, que, até então, estava fundada em critérios de autenticidade e de conservação, com foco nos objetos e nos bens materiais para garantia de sua longevidade e permanência, "a despeito" do tempo.

Percebe-se, por fim, que retirar um objeto de seu contexto social de uso e produçáo, declará-lo patrimônio, conservá-lo como uma peça única e colocá-lo num museu não abrange todas as situaçôes em que é possível reconhecer um valor cultural e preservá-lo. Não faz sentido, por exemplo, nos casos em que o que tem valor não é o objeto, inúmeras vezes rapidamente perecível ou consumível, importa saber produzi-lo. Não faz sentido, igualmente, nos casos em que nem mesmo há objetos, mas apenas palavras, sons, gestos e ideias (SANT’ANNA, 2009: 52-53).

Estes movimentos contemporâneos em curso nos processos educativos parecem-nos tributários das transformaçôes advindas tanto da Educação quanto do Patrimônio Cultural. Enumeramos três destas transformaçóes que constituem, a bem da verdade, desafios teórico-metodológicos deste contexto, dentre outras que, evidentemente, podem ser elencadas e discutidas. Sabemos, também, que nos processos educativos comparecem concepçôes contrastantes, por vezes contraditórias. Supóe-se, contudo, que estamos em momento desafiador para problematização, compreensão e usufruto do patrimônio, com deslocamentos visíveis e ressonantes.

Registros de bens patrimoniais identitários - incorporação de tradiçóes, bens e referenciais culturais marcados por traços identitários, rompendo-se com critérios de herança nacional, raridade, exclusividade, excepcionalidade e valor material. As repercussóes educativas são visíveis na ampliação da potencialidade de abordagem de bens culturais mais próximos das realidades dos sujeitos, com inclusão de indícios biográficos nas abordagens patrimoniais. Há expansão das noções de cultura e patrimônio, com inclusão de critérios de valor referencial e simbólico que não são intrínsecos aos valores materiais dos objetos e registros, mas que se ligam à atribuição de sentido pelos grupos e sujeitos de referência. Na relaçáo educativa, as repercussóes desta nova face do patrimônio são também visíveis por meio de açóes educativas em que, em jogos de escala, afirmam trânsitos entre referências culturais para grupos mais reservados e referências culturais nacionais, democratizando o direito à memória e estimulando, nos processos educacionais, a análise de dimensôes políticas e biográficas do patrimônio.

Reconhecimento de patrimônios náo consagrados - o reconhecimento, no ato educativo, da potencialidade da noção de patrimônio - e não de sua exclusi- 
vidade - tem repercussóes educativas visíveis. Ao admitir a face sempre expansível do patrimônio, o educador estará convocando à análise pó/ética e política do mesmo. Sendo poética, esta análise poderá dimensionar os gestos, critérios, sensibilidades e ancoragens sociais e culturais envolvidos nos procedimentos de eleição de registro e salvaguarda dos bens patrimonializados. Ao mesmo tempo, fará análise política das manifestaçóes e registros culturais que têm potencialidade para estudo e usufruto do patrimônio, compreendido como prática de atribuição de valor, não como resultado, definitivo e estático, de um universo consagrado. Neste caso, o patrimônio é compreendido mais como prática e processo, como gesto e como símbolo do que como resultado estável. Sendo assim uma prática, aliás, mutável no tempo e em conformidade com os valores de cada época, o processo do patrimônio pode proporcionar o exercício de investigação nos atos educativos, com experiências de pesquisa das realidades de inserção dos sujeitos e com enunciação de valores patrimonializáveis potentes para uma comunidade.

Ao mesmo tempo, estes gestos educativos podem, de fato, repercutir em processos reais de registro e preservação, fazendo com que a problemática do patrimônio não seja vivida como algo externo aos sujeitos que vivem o processo cultural, mas como parte de sua vida em curso. Essa nova acepção requer modificaçóes da noção de autenticidade, incorporando a mutabilidade cultural própria à pluralidade da experiência que marca o patrimônio imaterial e os processos identitários. Expande-se, também, o conceito de identidade cultural, incorporando necessária acepção que inclui todas as formas identitárias que compóem a dinâmica cultural. Disso decorre, também, a criação de propostas educativas mais democráticas, inclusivas e, também, plurais. Vemos promoverem-se rupturas no modelo preservacionista que traduzia, para a educação, noçóes estreitas de autenticidade e de exemplaridade do registro patrimonial, cuja centralidade recaía sobre abordagem exógena dos bens e registros de patrimônio, com pouca implicação subjetiva, intersubjetiva e social.

Consideração do caráter intersubjetivo, sensível, multidirecional e relacional do patrimônio - Os processos educativos são atravessados por dimensóes objetivas, subjetivas e intersubjetivas. Compreende-se uma educação voltada ao patrimônio, na contemporaneidade, como aquela capaz de fazer da partilha do sensível (RANCIÈRE, 2009a) o motivo do usufruto e compreensão do patrimônio, evidentemente não sem tensões. Afirma-se uma educação em que estão presentes manifestaçóes face ao visível, aos silêncios, à repulsa, aos desejos, e a todas as manifestaçóes inconscientes, não perceptíveis ou palpáveis, mas tocantes, pulsantes (RANCIĖRE, 2009b). Disso decorre uma alteração de foco de abordagem centrada na relação entre os sujeitos e deles com os bens e referências culturais na partilha da cultura. Emergem, neste cenário, projetos educativos marcados pela abordagem de dimensóes sensíveis do patrimônio, compreendendo-se o sensível em sua estreita vinculação com a ética e a política (RANCIÈRE, 2009), convidando à negação da estetização do patrimônio (CANCLINI, 2011) na abordagem educativa. Além disso, aos processos educativos mais elaborados comparecem abordagens sistêmicas e multidirecionais do patrimônio, evitando-se a sua localizaçáo exclusiva no passado (portanto, com análise dos trânsitos e interseçóes temporais), distanciando-se da abordagem de registros e fatos históricos isolados (mas privilegiando as relações entre os bens e manifestaçóes culturais) e garantindo a emergência de problemáticas do presente na compreensão da face educativa do patrimônio. Compreende-se, também, os desafios postos aos docentes neste novo cenário, em que as biografias (inclusive as dos sujeitos presentes ao ato educativo) são convocadas, contrastadas e compartilhadas na história. 
Todas estas convocaçóes enunciam as correlações entre educação, política, ética e sensibilidades, presentes neste novo tempo de usufruto e experiência do patrimônio pelos sujeitos da Educação. E, sabemos, há muitas outras transformações em curso nesse terreno em mutação.

\section{REFERENCIAS BIBLIOGRÁFICAS}

BURKE, Peter. "Centenários e milênios”. In: BURKE, Peter. O Historiador Como Colunista. Rio de Janeiro: Ed. Civilização Brasileira, 2009.

CANCLINI, Néstor Garcia. "O Patrimônio Cultural e a construção imaginária do nacional". In: Cidade. Revista do Patrimônio Histórico e Artístico Nacional, no 23, 1994.

Culturas Hibridas. Estratégias para Entrar e Sair da Modernidade. São Paulo: Edusp, 2011.

CONSTITUIÇÃO DA REPÚBLICA FEDERATIVA DO BRASIL, 1988.

FERNANDES, J. Ricardo Oriá. "Educação patrimonial e cidadania: uma proposta alternativa para o ensino da história". In: Memória, História e Historiografia. Revista Brasileira de História. São Paulo: ANPUH/Marco Zero, vol. 13, no 25/26, setembro 92/agosto 93.

FONSECA, Maria Cecília Londres. "O Patrimônio Histórico na sociedade contemporânea”. In: ESCRITOS. Revista da Casa de Rui Barbosa. Ano 1, n. 1, 2007.

FUNARI, Pedro Paulo e PELEGRINI, Sandra C.A. Patrimônio Histórico e Cultural. Rio de Janeiro: Jorge Zahar Ed., 2006. Col. Ciências Sociais Passo a Passo.

GONÇALVES, José Reginaldo Santos. "O patrimônio como categoria de pensamento”. In: ABREU, Regina. CHAGAS, Mario. Memória e Patrimônio: Ensaios Contemporâneos. Rio de Janeiro: Lamparina, 2009.

HUYSSEN, Andreas. Seduzidos pela Memória: Arquitetura, Monumentos, Midia. Rio de Janeiro: Aeroplano, 2000.

HORTA, Maria de Lourdes et al. Guia Básico de Educação Patrimonial. Brasília: Instituto do Patrimônio Histórico e Artístico Nacional, Museu Imperial, 1999.

LE GOFF, Jacques. História e Memória. Campinas, SP: Editora da Unicamp, 1990.

NORA, Pierre. "Memória: da liberdade à tirania". In: MUSAS-Revista Brasileira de Museus e Museologia, n. 4, 2009. Rio de Janeiro: IBRAM, 2009.

RANCIÈRE, Jacques. A Partilha do Sensivel. Estética e Politica. São Paulo: Editora 34, 2009a.

. O Inconsciente Estético. São Paulo: Editora 34, 2009b.

RICOUER, Paul. A Memória, a História e o Esquecimento. Campinas, São Paulo: Editora da UNICAMP, 2007.

SANTANNA, Márcia. "A face imaterial do patrimônio cultural: os novos instrumentos de reconhecimento e valorização". In: ABREU, Regina. CHAGAS, Mario. Memória e Patrimônio: Ensaios Contemporâneos. Rio de Janeiro: Lamparina, 2009.

SILVA, Álvaro Costa e. “Um breve histórico do Patrimônio.” In: Memória e Educação. Rio de Janeiro: Instituto Brasileiro do Patrimônio Cultural. Departamento de Promoção, Paço Imperial, 1992. 